\title{
BMJ Open Assessment of the use of Unna boot in the treatment of chronic venous leg ulcers in adults: systematic review protocol
}

Thalita Paranhos, Caroline S B Paiva, Fernanda C I Cardoso, Priscila P Apolinário, Flavia Figueiredo Azevedo, Maria G B Saidel, Henrique C Oliveira, Ariane P Dini, Ana R S O Kumakura, Maria H Melo Lima

To cite: Paranhos T, Paiva CSB, Cardoso FCl, et al. Assessment of the use of Unna boot in the treatment of chronic venous leg ulcers in adults: systematic review protocol. BMJ Open 2019;9:e032091. doi:10.1136/ bmjopen-2019-032091

- Prepublication history and additional material for this paper are available online. To view these files, please visit the journal online (http://dx.doi org/10.1136/bmjopen-2019032091).

Received 04 June 2019 Revised 29 0ctober 2019 Accepted 11 November 2019

D) Check for updates

(c) Author(s) (or their employer(s)) 2019. Re-use permitted under CC BY-NC. No commercial re-use. See rights and permissions. Published by BMJ.

School of Nursing, State University of Campinas, Campinas, São Paulo, Brazil

Correspondence to Dr Maria H Melo Lima; melolima@unicamp.br

\section{ABSTRACT}

Introduction Chronic venous insufficiency (CVI) is an anomaly of the normal functioning of the venous system caused by valvular incompetence with or without the obstruction of venous flow. This condition can affect either or both of the superficial and the deep venous systems. Venous dysfunction can even result in congenital or acquired disorders, and its complications include venous leg ulcers (VLUs). The objective of this systematic review is to determine the effectiveness of Unna boot in the treatment of wound healing of VLU by assessing the quality of the available evidence.

Methods and analysis A literature search in PubMed, CINAHL, Scopus, Web of Science, Cochrane Library, BVS/ BIREME, Embase, ProQuest, BDTD, Thesis and Dissertation Catalog, Sao Paulo Research Foundation/Thesis and dissertation, OPEN THESIS, A service of the US National Institute of Health, Center for Reviews and DisseminationUniversity of New York and SciElo published in the last 10 years, the period from January 1999 to March 2019. The review will include primary studies (original), and Controlled Trials or Observational studies (crosssectional, case-control or longitudinal studies) with VLU. The exclusion will include leg ulceration due to different causes, such as pressure, arterial, diabetic or mixedaetiology leg ulcers. Data synthesis will be performed using a narrative summary and quantitative analysis. Ethics and dissemination This systematic review does not require approval by the ethics committee, as individual patient data will not be collected. Dissemination of findings will be through publications in peer-reviewed journals and/ or via conference presentations.

\section{PROSPERO registration number CRD42019127947}

\section{BACKGROUND}

Chronic venous insufficiency (CVI) is a condition that affects the venous system of the lower limbs, resulting in pain, skin changes and ulcerations. ${ }^{1}$ Abnormalities and weaknesses in the surface vein wall may hinder the blood flow from the deepest veins to the heart. In that case, venous valve insufficiency is the main cause of impaired
Strengths and limitations of this study

- Knowing the effectiveness of Unna boot dressing in the management of venous leg ulcer (VLU) will contribute to the use of a low-cost alternative to wound healing. VLUs has not been studied; our systematic review will be the first to answer the question.

- The eligibility criteria used may not result in the selection of studies that are homogeneous in methods, limiting the ability to draw reliable conclusions.

- Only articles published in English, Spanish and Portuguese will be considered.

flow in the deep veins of the lower limbs. When this problem occurs, the superficial veins become engorged with blood, and the walls become dilated and permeable to the release of substances normally contained in the vessel. ${ }^{23}$ Deep veins are most affected by an acute obstruction (deep vein thrombosis) or chronic damage (stenosis and occlusion) caused by post-thrombotic changes or trauma. ${ }^{4-7}$

Acute and chronic deep vein obstruction limits blood flow, resulting in increased venous pressure with muscle contraction and secondary muscle pump dysfunction. ${ }^{5-8}$ CVI can be diagnosed using ultrasound techniques to detect venous reflux and blood accumulation in the deep veins of the legs. ${ }^{45}$ External compressive therapy is recommended to reverse the high pressure of the venous system to prevent complications, such as venous leg ulcer (VLU), or to improve venous return to close such ulcers. ${ }^{7-9}$

Compressive therapies can be elastic, inelastic and pneumatic. Among inelastic therapies, there are several brands available in the market, such as econo-paste (Hartmann), gelocast (BSN medical) Viscopaste (Smith \& Nephew) and Flexdress (ConvaTec). These 
products, known as Unna Boot, are bandages consisting of a low compression gauze $(18-24 \mathrm{~mm} \mathrm{Hg})$ and impregnated with oxide of zinc, gum acacia, glycerol, castor oil and deionised water, resulting in a semi-solid mould for external compression. ${ }^{1011}$

Unna Boot is an inelastic compression therapy that acts to increase compression and promote drainage and venous support, improving the healing of the ulcer. ${ }^{6} 1011$ The compression, during rest and muscle contraction, acts on the macrocirculation, increasing the venous return, and on the tissue pressure, supporting the reabsorption of the oedema and the return of the fluids located in the interstitial spaces to the interior of the vascular and lymphatic system. This process promotes the healing of the lesion and prevents inflammation. ${ }^{7-9} 11$ According to studies, the use of the Unna Boot is effective in promoting the satisfaction related to minimum wound care, rapid development of granulation tissue, improvement in comfort and cost savings compared with similar compressions. $^{811}$

This systematic review aims to determine the effectiveness of Unna boot in the treatment of wound healing of VLU by assessing the quality of the available evidence. The specific question addressed by the review is: Is the use of Unna boot effective in the treatment of chronic VLU in adults?

\section{METHODS}

This protocol has been registered with the PROSPERO (CRD42019127947) and will be reported following the Preferred Reporting Items for Systematic Review and meta-Analysis Protocols (PRISMA). ${ }^{12} 13$ This review will be reported following standardised critical appraisal instruments from the Joanna Briggs Institute (JBI). ${ }^{14} 15$

\section{Patient and public involvement}

No patients nor the general public were directly involved in the development of this systematic review protocol.

\section{Search strategies}

We will systematically and electronically conduct searches on the following databases: PubMed (1999-2019), PubMed/PMC(1999-2019), Virtual Health Library (BVS/BIREME) (1999-2019), The Cumulative Index to Nursing and Allied Health Literature (CINAHL) (19992019), Scopus (1999-2019), Web of Science (1999-2019), MEDLINE (CAPES) (1999-2019), Embase (1999-2019), Cochrane Library (1999-2019), ProQuest (1999-2019), Brazilian Digital Library of Theses and Dissertations (BDTD) (1999-2019), CAPES/Thesis and Dissertation Catalog (1999-2019) Sao Paulo Research Foundation/ Thesis and dissertation (1999-2019), OPEN THESIS (1999-2019), A service of the US National Institutes of Health (Clinical Trial) (1999-2019), Centre for Reviews and Dissemination-University of York (1999-2019), Scientific Electronic Library (SciELO) (1999-2019). The full search strategy is displayed in the online supplementary appendix 1 .

\section{Selection criteria}

The inclusion criteria will be: all human studies about inelastic compression therapy, treatment that combines zinc oxide paste and compression bandages for treating VLU, and in which, medical diagnosis of CVI by Doppler ultrasound examination was used.

The searches were conducted evaluating the period from January 1999 to March 2019.

\section{Study design}

To be included, studies need to be primary (original), controlled trials or observational studies (cross-sectional, case-control or longitudinal studies). These studies will be used to assessing the effectiveness of Unna boot on the healing of VLU. Eligible studies must be in Portuguese, Spanish or English language.

\section{Type of participants}

The participants are all adult patients with VLU of any location and size. We will only accept studies in which authors used Doppler ultrasound to confirm wound aetiology. The intervention of interest is Unna boot. We will exclude studies about leg ulceration of different causes, such as pressure, arterial, diabetic or mixed aetiology leg ulcers.

\section{Intervention}

The intervention will include the Unna boot treatment of VLU. Information about the time of use, initial wound size, sociodemographic and clinical will be documented.

\section{Comparator}

Studies comparing any other type of dressing, topical agent, placebo or a standard treatment will be included in this review.

\section{Outcome measures}

The primary outcome measures are the proportions of wounds with complete healing. We will consider the proportion of ulcers healed during follow-up and frequency of complete healing during the study. The rate of adverse effects and events (eg, the wound infection rate and signs and symptoms of clinical infection) will be documented. Additional outcome(s), such as quality of life (measured using a generic questionnaire or a diseasespecific questionnaire) and pain (eg, at dressing change or over the course of treatment) will be only included in validated questionnaires or visual analogue scales. Change in ulcer size will be considered using data on the change (and percentage change) in ulcer size, with adjustment for baseline size (we will contact study authors to request adjusted means when not available).

\section{Study selection and data management}

Two review authors will independently assess the titles and abstracts of studies found during the searches for 
potential inclusion in this review. Disagreements will be discussed during consensus meetings with a third review author. Potentially relevant studies will be examined in full by two review authors. The studies that meet the eligibility criteria will be included in the review. Disagreements will be discussed in consensus meetings with a third review author.

\section{Data extraction}

For data extraction, extracted information will include the study setting, study characteristics (authors, year of publication, country of publication and study design), details of the intervention and control, research design, inclusion and exclusion, outcomes, characteristics of the examined patient demographics (number of subjects, gender, mean age, comorbidities and number of wounds treated), wound characteristics (mean wound duration and mean wound size) losses to follow-up, sensitivity analysis, author conclusions and conflicts of interest. The disease type and stages of VLU will be identified in the studies by clinical, aetiological, anatomical and pathological elements for the classification of CVI, ${ }^{4}$ and an attempt will be made to identify whether the second component of compression was a short-stretch or long-stretch bandage. The origin of the ulcer will be identified and grouped in primary, post-thrombotic disease and recurrent as needed. Failed attempts will be discussed. Data extraction will again be performed independently by two reviewers and any discrepancies will be resolved through group discussion.

\section{Assessment of risk of bias of included studies}

Two reviewers will independently assess the quality of the included studies by using the standardised critical appraisal instruments from the JBI. ${ }^{14}$ The instruments require the following data: title, authors, year of publication, journal, methodology, method, data analysis employed, configuration, geographical and cultural context, participants, interventions, main results and conclusions of authors and reviewers. After extracting the data, a level of credibility will be assigned to each finding, and the results will be synthetised through groups of data from primary studies. Disagreements between reviewers over the quality checklist will be resolved through discussion.

\section{Data analysis and synthesis}

Data synthesis will be performed using a narrative summary and quantitative analysis. A meta-analysis considering models of random effects will be employed to compare among groups based on outcome variables if studies included in the review disclose sufficient data.

\section{DISCUSSION}

This review aims to determine the effectiveness of Unna boot of the treatment of wound healing in VLU. This assessment will be performed by evaluating the total proportion of completely closed wounds relative to that of the start of treatment. Although studies have shown good results with granulation tissue formation and wound healing, ${ }^{11}{ }^{16}$ the effectiveness is currently unclear. To our knowledge, this is the first systematic review to evaluate the effectiveness of the Unna boot on wound healing. The result of this review may help health professionals and educators recommend the use of inelastic compression for patients with VLU, especially where financial resources are scarce.

Contributors MHML, TP, FCIC and MGBS: study was conceptualised. PPA: developed the search strategy. CSBP, MGBS and FA: completed the search and drafted the protocol. APD, ARSO-K, MGBS and HCO: critically appraised the protocol and also contributed to its development by revising subsequent versions. MHML; ARSO-K and HCO: will contribute equally to the data collection and analysis, as well as the interpretation of the review. All authors will revise critically the review and will read and approved the final manuscript.

Funding The authors have not declared a specific grant for this research from any funding agency in the public, commercial or not-for-profit sectors.

Competing interests None declared.

Patient consent for publication Not required.

Ethics approval This systematic review does not require approval by ethics committee, as individual patient data will not be collected. Dissemination of findings will be through publications in peer-reviewed journals and/or via conference presentation.

Provenance and peer review Not commissioned; externally peer reviewed.

Data availability statement Data are available in a public, open access repository. There are no data in this work. Data are available upon reasonable request. Data may be obtained from a third party and are not publicly available. All data relevant to the study are included in the article or uploaded as supplementary information.

Open access This is an open access article distributed in accordance with the Creative Commons Attribution Non Commercial (CC BY-NC 4.0) license, which permits others to distribute, remix, adapt, build upon this work non-commercially, and license their derivative works on different terms, provided the original work is properly cited, appropriate credit is given, any changes made indicated, and the use is non-commercial. See: http://creativecommons.org/licenses/by-nc/4.0/.

ORCID iD

Maria H Melo Lima http://orcid.org/0000-0001-6521-8324

\section{REFERENCES}

1 Zarchi K, Jemec GBE. Delivery of compression therapy for venous leg ulcers. JAMA Dermatol 2014;150:730-6.

2 Alavi A, Sibbald RG, Phillips TJ, et al. What's new: management of venous leg ulcers: treating venous leg ulcers. J Am Acad Dermatol 2016;74:643-64.

3 Pascarella L, Shortell CK. Medical management of venous ulcers. Semin Vasc Surg 2015;28:21-8.

4 Eklöf B, Rutherford RB, Bergan JJ, et al. Revision of the CEAP classification for chronic venous disorders: consensus statement. $J$ Vasc Surg 2004;40:1248-52.

5 O'Meara S, Cullum N, Nelson EA, et al. Compression for venous leg ulcers. Cochrane Database Syst Rev 2012.

6 Nicolaides AN, Allegra C, Bergan J, et al. Management of chronic venous disorders of the lower limbs: guidelines according to scientific evidence. Int Angiol 2008;27:1-59.

7 Clark M. Understanding compression therapy: EWMA position Doc. compression bandages: principles and definitions; 2003: 5-7.

8 Harding KG, Vanscheidt W, Partsch $\mathrm{H}$, et al. Adaptive compression therapy for venous leg ulcers: a clinically effective, patient-centred approach. Int Wound J 2016;13:317-25.

9 Dabiri G, Hammerman S, Carson P, et al. Low-grade elastic compression regimen for venous leg ulcers - an effective compromise for patients requiring daily dressing changes. Int Wound J 2015;12:655-61.

10 Fonseca C, Franco T, Ramos A, et al. [The individual with leg ulcer and structured nursing care intervention: a systematic literature review]. Rev Esc Enferm USP 2012;46:480-6.

11 Luz BSR, Araujo CS, Atzingen DANCV, et al. Evaluating the effectiveness of the customized Unna boot when treating patients with venous ulcers. An Bras Dermatol 2013;88:41-9. 
12 Shamseer L, Moher D, Clarke M, et al. Preferred reporting items for systematic review and meta-analysis protocols (PRISMA-P) 2015: elaboration and explanation. BMJ 2015;349.

13 Moher D, Shamseer L, Clarke M, et al. Preferred reporting items for systematic review and meta-analysis protocols (PRISMA-P) 2015 statement. Syst Rev 2015;4:1.

14 The Joanna Briggs Institute. Joanna Briggs Institute Reviewer's Manual. The Joanna Briggs Institute, 2014.
15 The Joanna Briggs Institute. The Joanna Briggs Institute Reviewers' Manual 2015: Methodology for JBI Umbrella reviews. Joanne Briggs Inst, 2015.

16 Cardoso LV, de Fátima Guerreiro Godoy M, Czorny RCN, et al. Using bioelectrical impedance analysis to compare the treatment of edema with the Unna's boot and noncompression in individuals with venous ulcers. J Vasc Nurs 2019;37:58-63. 